\title{
FEMINICÍDIO E A PEC 181-A: AS CONQUISTAS FEMINISTAS E 0 RETROCESSO CONSERVADOR
}

\section{THE FEMINICIDE AND COSTITUTIONAL AMENDMENT PURPOSE 181-A; THE FEMINIST CONQUER AND THE CONSERVATIVE BACKLASH}

\author{
Larissa Gabriela Cruz Botelho*
}

\begin{abstract}
Resumo: $O$ presente artigo discute os avanços legislativos, bem como jurisprudenciais, dos últimos anos no que se refere às agendas feministas, em contraposição à Proposta de Emenda Constitucional 181-A, de autoria do deputado Tadeu Madulen, cuja inserção do termo inicial de proteção da vida poderia obstaculizar o debate sobre o aborto no Brasil, além de ensejar inúmeras ações de inconstitucionalidade a respeito das possibilidades de aborto do Código Penal. Desde a publicação da Lei Maria da Penha em 2006, muitas outras pautas feministas ocuparam não somente o Parlamento, como também os tribunais superiores, originando uma profusão de enunciados sumulares e leis de proteção à mulher. Ao final, trava-se um diálogo com o artigo de Márcia Tiburi, no qual a autora explana as formas de manifestação do patriarcado, excluindo as mulheres do debate.
\end{abstract}

Palavras-chave: Feminicídio. Aborto. Feminismo. Espaços de fala.

Abstract: This article discusses the legislative and jurisprudential advances of recent years in feminist agendas, as opposed to Proposed Constitutional Amendment 181A, authored by Congress man Tadeu Madulen, whose insertion of the original term of protection of life could hinder the debate on abortion in Brazil, as well as provoking numerous unconstitutional actions regarding the abortion possibilities of the Penal Code. Since the publication of the Maria da Penha Law in 2006, many other feminist guidelines have occupied not only the Parliament, but also the higher courts, giving rise to a plethora of summits and laws protecting women. At the end, a dialogue with the article by Márcia Tiburi, in which the author explains the forms of manifestation of the patriarchy, excluding the women from the debate.

Keywords: Feminicide. Abortion. Feminism.

\footnotetext{
*Professora auxiliar da Universidade Veiga de Almeida, professora auxiliar da Universidade Cândido Mendes e professora convidada da Universidade do Estado do Rio de Janeiro. Possui graduação em Direito pela Universidade Federal do Rio de Janeiro (2013) e mestrado em Direito pela Universidade do Estado do Rio de Janeiro (2016). Atualmente é consultora jurídica e tem experiência na área de Direito, com ênfase em Direito Penal, atuando principalmente nos seguintes temas: descriminalização do aborto, execução penal, adequação social, aborto e cyber terrorismo.
} 


\section{INTRODUÇÃO}

Ainda no século XXI, no Brasil, a religião pauta questões que deveriam estar afetas tão somente à saúde feminina. Homens e instituições ocupadas predominantemente por eles teorizam acerca do aborto, rechaçando aquelas a quem realmente interessa o debate.

O Brasil ainda criminaliza o aborto voluntário, ao contrário de países com uma realidade próxima, como o Uruguai, ou países supostamente desenvolvidos, como os Estados Unidos, que em alguns estados se permite o aborto.

Isso se deve, fundamentalmente, a duas questões: à tradição secular judaico-cristã que condena veementemente o aborto e à posição hegemônica masculina que ocupa os espaços de poder, ou como Tiburi menciona, os espaços de fala.O que se mostra paradoxal é que um assunto afeto ao interesse exclusivo da mulher é debatido por homens, sem sequer que as mulheres, realmente afetadas, sejam ouvidas.

Ainda com forte obstaculização do patriarcado machista e conservador, o movimento feminista cresceu nos últimos anos. Aos poucos, leis de enfrentamento da violência contra mulher foram sancionadas, condicionando a atenção da sociedade a esse assunto tão candente no país.

Em 2016, a proteção à mulher foi alçada a um novo patamar de proteção jurídico-penal: a inclusão do feminicídio, como homicídio qualificado. A rigor, a Lei do Feminicídio não inclui um novo tipo penal, apenas qualifica o homicídio da mulher em razão da sua condição de mulher.

A lei foi resultado de uma Comissão Parlamentar Mista de Inquérito presidida e relatada por mulheres que descortinouem números a morte de mulheres no Brasil, os estados mais violentos e quais as violências eram praticadas.

Do lado diametralmente oposto, a Proposta de Emenda Parlamentar, 181-A, de autoria do deputado Tadeu Mudalen, propõe a inclusão na Constituição Federal no Art. $1^{\circ}$, como fundamento da República Federativa do Brasil, a dignidade da pessoa humana, desde a concepção. 
Na prática, essa construção constitui uma obstrução do debate jurídicoa respeito do aborto e mais: pode-se rediscutir os casos de aborto já permitidos pelo Código Penal, no Art. 128.

Nesse diapasão, o presente artigo se presta à análise dos influxos dos movimentos feministas em contraposição à bancada conservadora na produção legislativa de normas penais, notadamente de condutas tendentes a abolir direitos jáconquistados pelas mulheres.

Em seguida, traça-se um diálogo com o artigo da filósofa Márcia Tiburi em que a autora desvenda a manifestação do patriarcado, expurgando as mulheres do debate, relegando-asa figurantes, coadjuvantes, de assuntos afetos aos seus próprios corpos.

\section{FEMINICIDIO E A CONQUISTA DO MOVIMENTO FEMINISTA}

O feminicídio é, assim como determina o art. 121 do Código Penal, o homicídio da mulher por razões da condição de sexo feminino e foi introduzida no ordenamento jurídico brasileiro a partir da Lei 13.104 de 09 de março de 2015.

A referida lei foi resultado do trabalho árduo e profícuo da Comissão Parlamentar Mista de Inquérito instituída com a finalidade de investigar a situação de violência contra a mulher no Brasil e as omissões do poder público no combate a essa violência.

Importa ressaltar que a referida comissão foi integrada por três mulheres, sendo a presidente a deputada federal Jô Moraes (PCdoB/MG), a vice-presidente a deputada federal Keiko Ota (PSB/SP) e a relatora a senadora Ana Rita (PT/RS).

A rigor, a Lei 13.104 não introduz um novo crime ao Código Penal, mas tão somente uma qualificadora ao crime de homicídio e uma majorante ao feminicídio. $\mathrm{O}$ art. 121 do Código Penal que trata do crime de homicídio ficou acrescido, portanto, de um inciso, tornando o feminicídio crime de homicídio qualificado, do parágrafo $2^{\circ}$ A, meramente explicativo, e do parágrafo $7^{\circ}$, que insere efetivamente uma majorante que implicará em um aumento substancial de pena ao condenado, de um terço até metade. 
Há quem aponte essa inovação como despropositada, uma vez que o magistrado, ao sentenciar, poderia adequar à conduta, homicídio contra a mulher, e às circunstâncias à qualificação torpe do homicídio (Art. 121, $2^{\circ}, \mathrm{I}, \mathrm{CP}$ ), igualmente, qualificado. Contudo, não era esseo tratamento destinado às inúmeras mortes de mulheres trazidas à baila por ocasião da Comissão Parlamentar Mista de Inquérito apresentada em 2013.

A Comissão desnudou em números as mortes de mulheres em 10(dez) estados da Federação, revelando uma face ainda mais cruel do descaso público: a inércia estatal.A violência contra a mulher não era alvo de debate e interesse no cenário público.As diversas formas de violências contra o sexo feminino eram menosprezadas, aviltando-se, por conseguinte, o direito mais básico do ser humano, a vida.

Esse cenário de desapreço à situação de violência sistêmica contra a mulher é, em grande medida, fruto de uma ocupação predominantemente masculina nos espaços de debate.É óbvio constatar que, por leviandade ou negligência, a causa feminista não ocupava as pautas de discussão no parlamento brasileiro.

Nesse ponto, especificamente, e em momento oportuno, far-se-á um diálogo com o artigo da filósofa e feminista Márcia Tiburi, $\mathrm{O}$ aborto e a bondade das pessoas do bem.

\subsection{A Comissão Parlamentar Mista de Inquérito e a Lei 13.104/2015}

No Brasil, a Lei do Feminicídio não é a primeira manifestação de políticacriminal voltada ao enfrentamento da violência contra a mulher. A Lei Maria da Penha, Lei 11.340 de 2006, é a primeira legislação orientada nesse sentido.

No que se refere à Lei Maria da Penha, ela dá cumprimento à Convenção para Prevenir, Punir e Erradicar a Violência contra a Mulher, a Convenção de Belém do Pará, da Organização dos Estados Americanos (OEA), ratificada pelo Brasil em 1994, e à Convenção para Eliminação de Todas as Formas de Discriminação contra a Mulher (Cedaw), da Organização das Nações Unidas (ONU). 
Ao contrário do que se pode cogitar, não houve um incremento de tipos penais no Código Penal, mas uma extensão de medidas protetivas de urgência destinadas à mulher em situação de violência. ${ }^{1}$

Nesse sentido, a Lei 12.403 de 2011 também introduziu a possibilidade de prisão preventiva do agressor quando o crime envolver violência doméstica e familiar contra a mulher, criança, adolescente, idoso, enfermo ou pessoa com deficiência, para garantir a execução das medidas protetivas de urgência. ${ }^{2}$

A Lei 13.257 de 8 de março de 2016, alcunhada de Estatuto da Primeira Infância, instituiu políticas públicas para a primeira infância, refletindo no Código de Processo Penal, notadamente no instituto da prisão domiciliar para mulheres com filhos menores de 12 anos. Importa ressaltar que a referida lei não foi projetadacom vistas à proteção da mulher, mas para as crianças em tenra idade. Obviamente, contudo, a lei resvala em um direito feminino que é a convivência coma prole.

Mais recentemente, a Lei 13.497 de 8 de novembro de 2017 acrescentou três dispositivos à Lei Maria da Penha, quais sejam: os artigos 10- $\mathrm{A}^{3}, 12-\mathrm{A}^{4}$ e $12-\mathrm{B}^{5}$, esse último teve seu caput vetado, somente mantendo o parágrafo $3^{\circ}$.

\footnotetext{
${ }^{1}$ Recomenda-se a leitura do artigo: COSTA, R. S.; OLIVEIRA, A. V. Lei 11.340/06 e sistema penal: o quão punitivo são os juizados de violência doméstica e familiar contra a mulher. In: Juliana Teixeira Esteves, José Luciano Albino Barbosa, Pablo Ricardo de Lima Falcão. (Org.). Direitos, gênero e movimentos sociais II. Florianópolis: CONPEDI, 2014. v. 1, p. 267-282.

2 Art. 313. Nos termos do art. 312 deste Código, será admitida a decretação da prisão preventiva:

III - se o crime envolver violência doméstica e familiar contra a mulher, criança, adolescente, idoso, enfermo ou pessoa com deficiência, para garantir a execução das medidas protetivas de urgência; (grifo do autor).

${ }^{3}$ Art. 10-A É direito da mulher em situação de violência doméstica e familiar o atendimento policial e pericial especializado, ininterrupto e prestado por servidores - preferencialmente do sexo feminino previamente capacitados. (Grifo do autor)

$\S 1$ - A inquirição de mulher em situação de violência doméstica e familiar ou de testemunha de violência doméstica, quando se tratar de crime contra a mulher, obedecerá às seguintes diretrizes:

II - garantia de que, em nenhuma hipótese, a mulher em situação de violência doméstica e familiar, familiares e testemunhas terão contato direto com investigados ou suspeitos e pessoas a eles relacionadas;

III - não revitimização da depoente, evitando sucessivas inquirições sobre o mesmo fato nos âmbitos criminal, cível e administrativo, bem como questionamentos sobre a vida privada.

§ 2 o Na inquirição de mulher em situação de violência doméstica e familiar ou de testemunha de delitos de que trata esta Lei, adotar-se-á, preferencialmente, o seguinte procedimento:

I - a inquirição será feita em recinto especialmente projetado para esse fim, o qual conterá os equipamentos próprios e adequados à idade da mulher em situação de violência doméstica e familiar ou testemunha e ao tipo e à gravidade da violência sofrida;

II - quando for o caso, a inquirição será intermediada por profissional especializado em violência doméstica e familiar designado pela autoridade judiciária ou policial;
} 
Enfatiza-se, nessa nova lei, a preferência de mulheres capacitadas no atendimento à mulher vítima de violência. $O$ parágrafo $1^{\circ}$ do Art. 10-A determina algumas diretrizes que deverão ser observadas durante a inquirição da mulher em situação de violência. Ressalta-se, dentre as orientações, a proibição do contato direto da mulher em situação de violência doméstica e familiar, familiares e testemunhas com investigados ou suspeitos e pessoas a eles relacionadas. Evidenciase também a não revitimização, isto é, evitar o quanto possível sucessivas inquirições, que, em alguma medida, reproduz o sofrimento já suportado.

O Art. 12-A dispõe que os Estados e o Distrito Federal, na sua formulação de políticas de atendimento à mulher em situação de violência doméstica e familiar, deverão dar prioridade à criação de Delegacias Especializadas de Atendimento à Mulher (DEAMs) e de Núcleos Investigativos de Feminicídio e de equipes especializadas para o atendimento e a investigação das violências graves contra a mulher.

O caput do Art. 12-B foi vetado pelo Presidente da República. O dispositivo vetado dispunha que o delegado de polícia, preferencialmente aquele lotado na Delegacia especializada, poderia aplicar provisoriamente, até deliberação judicial, as medidas protetivas de urgência previstas na Lei Maria da Penha.O veto foi fundamentado na reserva de jurisdição para aplicação das medidas protetivas.

$\mathrm{Na}$ seara mundial, as recomendações internacionais exigiam do país a tipificação do feminicídio. A título exemplificativo, cita-se o Relatório sobre Violência contra Mulheres, suas Causas e Consequências, assinado por Rashida Manjoo, apontado no Relatório da Comissão Mista Parlamentar de Inquérito.

Evidentemente, e essa importância é ressaltada no relatório da referida comissão, outras medidas devem ser adotadas para o atendimento de mulheres em situação de violência doméstica.

III - o depoimento será registrado em meio eletrônico ou magnético, devendo a degravação e a mídia integrar o inquérito.

${ }^{4}$ Art. 12-A: Os Estados e o Distrito Federal, na formulação de suas políticas e planos de atendimento à mulher em situação de violência doméstica e familiar, darão prioridade, no âmbito da Polícia Civil, à criação de Delegacias Especializadas de Atendimento à Mulher (Deam), de Núcleos Investigativos de Feminicídio e de equipes especializadas para o atendimento e a investigação das violências graves contra a mulher. (Grifo do autor)

${ }^{5}$ Art. 12-B. (VETADO). § 3 A autoridade policial poderá requisitar os serviços públicos necessários à defesa da mulher em situação de violência doméstica e familiar e de seus dependentes. 
Além das medidas de política-criminal, o judiciário deve garantir, em atenção ao princípio da celeridade e duração razoável do processo, uma instrução, julgamento e execução em um espaço razoável de tempo. Dessa forma, evita-se a prescrição dos crimes e põe fim à tradição de conivência entre o judiciário e a morte de mulheres.

Nesse sentido, a Lei 13.285 de 2016 introduziu o art. 394-A que determina a preferência de tramitação de crimes hediondos, incluindo, por conseguinte, o crime de feminicídio.

O relatório da comissão destaca, ainda, a dificuldade em se obter dados estatísticos nos estados pesquisados que indicassem quantas mulheres foram vítimas de violência e qual o bem jurídico violado, se a vida, se a integridade física, se a dignidade sexual, se outros.Isso sinaliza sobretudo o pouco interesse- ou nenhumdas secretarias de segurança pública estaduais em saber quantos crimes aconteceram, qual o período, as circunstâncias e traçar um perfil - se possível- da mulher vítima de violência.

A quantificação de crimes, perfil das vítimas, circunstâncias que envolviam cada crime é de fundamental importância para orientar políticas de segurança pública. Sem esses dados, não é possível orquestrar medidas efetivas e incisivas capazes de dirimir a violação ao direito mais básico do cidadão, a vida.

O trabalho final da comissão apontou, ainda, a aplicação da Lei 9.099 de 1995 para crimes que envolviam violência doméstica e familiar em alguns estados, tanto nas capitais, mas sobretudo no interior, o que é expressamente vetado pela Lei Maria da Penha em seu artigo $41 .^{6}$

Ressalva-se, não obstante, que o referido documento foi apresentado no ano de 2013. Em junho de 2015, o Superior Tribunal de Justiça editou a súmula 536, a qual dispõe que "a suspensão condicional do processo e a transação penal não se aplicam na hipótese de delitos sujeitos ao rito da Lei Maria da Penha." 7

\footnotetext{
6 Art. 41. Aos crimes praticados com violência doméstica e familiar contra a mulher, independentemente da pena prevista, não se aplica a Lei no 9.099, de 26 de setembro de 1995.

7 Disponível em:

http://www.stj.jus.br/SCON/sumulas/toc.jsp?livre=536\&\&b=SUMU\&thesaurus=JURIDICO\&p=true. Acesso em: 15 fev. 2018.
} 
Em setembro de 2017, o STJ também editou a Súmula 588 que reza "a prática de crime ou contravenção penal contra a mulher com violência ou grave ameaça no ambiente doméstico impossibilita a substituição da pena privativa de liberdade por restritiva de direitos". A referida súmula põe fim à tradição de magistrados substituírem no édito condenatório os crimes de lesão corporal leve e vias de fato por restritivas de direito. Isso ocorria porque o art. 17 da Lei 11.340/2006 veda tão somente a pena de cesta básica ou outras penas pecuniárias, bem como a substituição de pena que implique o pagamento isolado de multa.

Outra súmula à respeito do tema foi editada no ano de 2017 pela Terceira Seção do Superior Tribunal de Justiça, a súmula 589 que diz: "é inaplicável o princípio da insignificância nos crimes ou contravenções penais praticados contra a mulher no âmbito das relações domésticas".

Sublinha-se o descaso reiterado, sistemático de alguns juízes em aplicar o referido princípio em casos que envolviam a violência doméstica. Cabe consignar que um dos pressupostos para a aplicação do princípio da insignificância é o reduzidíssimo grau de reprovabilidade do comportamento. ${ }^{8}$ Essa aberração jurídica é, sem sombra de dúvida, reflexos de uma sociedade extremamente machista, que culpabiliza as mulheres pelas agressões sofridas.

Quatro outras comissões parlamentares mistas foram instauradas nos anos de 1992, 2003, 2012 e 2013.

A primeira, em 1992, foi presidida pela deputada Sandra Starlig e apontou as seguintes conclusões: dificuldade no levantamento de dados, inexistência de uma nomenclatura unificada referente aos dados sobre violência contra a mulher e dados incompletos ou que chegaram tardiamente à CPI.

A segunda de 2003, CPMI da exploração sexual contra crianças e adolescentes presidida pela Senadora Patrícia Saboya, expôs a grave violação sexual de crianças e adolescentes, notadamente do sexo feminino.

\footnotetext{
8 "(...) O princípio da insignificância - que considera necessária, na aferição do relevo material da tipicidade penal, a presença de certos vetores, tais como (a) a mínima ofensividade da conduta do agente, (b) a nenhuma periculosidade social da ação, (c) o reduzidíssimo grau de reprovabilidade do comportamento e (d) a inexpressividade da lesão jurídica provocada (...)" Trecho retirado do sítio eletrônico: <http://www.stf.jus.br/portal/cms/verNoticiaDetalhe.asp?idConteudo=63002> última visualização em 16.02.2013.
} 
A CPI de 2012 constatou que nos últimos 30 anos, 91mil mulheres foram mortas, sendo que 43,5 mil só na última década. Isso representa um aumento de 217,6\%. Os estados da Federação Alagoas e Espírito Santo alternam-se nos primeiros lugares entre os estados mais perigosos.

Por fim, a quarta CPI do Tráfico de Pessoas, do Senado Federal, presidida pela Senadora Vanessa Grazziontin, revelou a imperiosa necessidade de se adequar a legislação da época aos avanços então necessários para proteção da mulher, vítima do tráfico nacional e internacional para fins de exploração sexuais. ${ }^{9}$

Nesse sentido, sublinha-se, a mulher é a maior vítima de crimes sexuais mais uma violência contra o copo da mulher-, conforme aponta o Dossiê Mulher do ano de 2017. (PINTO; MORAES; MANSO, 2017).

Conforme os dados recolhidos no ano de 2016, apenas no Rio de Janeiro, 4.705 mulheres foram vítimas de estupro - aqui se contabiliza apenas os estupros consumados. Esse valor corresponde a $85,3 \%$ do total de estupros notificados.

Destaca-se, contudo, que esse dado pode ser mais alarmante se considerados o número de vítimas que não notificaram o crime, seja por medo do agressor, seja por constrangimento.

Conquanto o homicídio seja, sem dúvida, a mais grave violação do direito da mulher, esse não encerra toda a sorte de violência perpetrada contra o sexo feminino. Destacam-se a violência patrimonial, sexual e moral nos mais diversos espaços sejam públicos sejam privados.

O relatório da comissão aponta que muitas mulheres optam por recorrer a familiares a ir à delegacia representar formalmente contra o seu algoz. Cerca de $55,7 \%$ de mulheres agredidas não procurou a polícia. Das que foram à delegacia policial e não representaram formalmente contra o seu agressor, destacam-se, fundamentalmente as seguintes razões: a) o fato de a polícia não querer fazer 0 registro; b) não queria envolver a polícia ou medo de represália; c) a falta de provas; e d) não acreditava na polícia.

\footnotetext{
${ }^{9}$ A Lei 13.344 de outubro de 2016 modificou o tratamento do tráfico internacional de pessoas, ampliando a tipificação não somente para tráfico de pessoas com finalidade sexual.
} 
A Central de Atendimento à Mulher - Ligue 180 -, desde a sua implementação apresenta um número crescente de ligações de 2006 a 2012. Em 2006, foram 46.423 ligações e em 2011, 667.116 ligações.

Não obstante os avanços em termos de política pública no enfrentamento as violências que vitimam as mulheres, a conscientização ainda é de impreterível e deinadiável necessidade.

Se por um lado há um avanço na democratização do debate, notadamente na participação de mulheres ocupando os espaços de fala, outrora afugentadas do cenário político, os homens também, no Senado Federal, discutem o que é mais conveniente ao corpo da mulher no que se refere ao aborto.

\section{O RETROCESSO CONSERVADOR: A PEC 181 DE 2015}

O Deputado Federal Jorge Tadeu Mudalen apresentou um apenso ao Projeto de Emenda Constitucional (PEC) 181 de autoria do senador Aécio Neves, a PEC 181A. A PEC 181, originalmente, propunha a alteração do artigo $7^{\circ}$, XVIII, da Constituição Federal, para estender o prazo de licença maternidade para o período de internação do recém-nascido, não ultrapassando, contudo, o prazo de duzentos e quarenta dias. ${ }^{1011}$

A Comissão Especial destinada a proferir parecer à respeito da PEC 181-A problematizou a, supostamente, indevida interferência de outros poderes em flagrante desrespeito aos limites constitucionais de atribuição, consagrados no Art. $2^{\circ}$ da Constituição do Brasil.

Propôs, então, a Comissão a discussão em torno de três eixos: a) dignidade da pessoa humana e o direito à vida; b) Estado de Direito; e, por fim, c) ativismo judicial. Dessa forma, foram realizadas audiência públicas e dois professores - sim, do sexo masculino-, foram ouvidos, os professores doutores Elival da Silva Ramos, professor titular da Universidade de São Paulo, e José Levi Mello do Amaral Júnior.

\footnotetext{
10 Para mais informações, consultar: http://camara.gov.br/proposicoesWeb/fichadetramitacao?idProposicao=2075449. Aceso em: 15 fev. 2018.
} 
O prof. Elival destacou o corrosivo ativismo judiciário, notadamente o do Supremo Tribunal Federal. Segundo ele, aos Tribunais não é dada a chancela de criar normas, porque não há escolha democrática de seus membros pelo voto popular. A eles é destinada, unicamente, a interpretação sistemática e teleológica.

No que diz respeito ao direito à vida, o professor Elival destacou que a preservação do direito à vida cabe ao parlamento, o qual possui a incumbência constitucional de determiná-la e discipliná-la.

O referido professor ressaltou, como exemplo de inadequação institucional do Poder Judiciário, a atuação do Supremo Tribunal Federal no caso dos fetos anencéfalos. Nesse caso, o STF teria criado mais uma hipótese de aborto, não prevista no Código Penal.

Destacou, nesse diapasão, a importância do procedimento legislativo, orientado por discussões, audiências públicas, apresentação de emendas, debates e votações, corroborando o processo democrático.

Ainda dentro dos debates da referida comissão, foi ouvido o Dr. Paulo Jacobina -sim, mais um homem-, procurador da República que destacou o paradoxo entre posturas e práticas científicas: se de um lado, recua-se no tempo gestacional para assegurar a vida do feto, por outro uma outra postura científica promoveria e facilitaria implacavelmente o aborto.

Esse mesmo doutor ressaltou que nos Estados Unidos, o aborto foi possível com o ativismo judicial, lastreado na tese de que o aborto é um direito unilateral da mulher. Contudo, defende ele, essa tese não é definitiva e deveria esse posicionamento ser revisto, permitindo a democratização do debate com a participação daqueles que discordam do aborto.

Aqui, uma ressalva importante: até esse instante, apenas homens que comungam de uma mesma ideologia política participaram do debate. Nenhuma mulher foi ouvida até a manifestação da professora Lília Nunes dos Santos.

Sublinhou a professora Lília dos Santos que o direito à liberdade não é absoluto aponto de permitir a supressão do direito à vida ao nascituro. Argumentouque todo direito fundamental tem um limite na ponderação, técnica interpretativa dos princípios constitucionais. Concluiu, dizendo: a Ação de 
Descumprimento de Preceito Fundamental $n^{\circ} 442$ pretendeu tornar absoluta o direito de escolha da mulher ao aborto.

Importante ressaltar que, por ocasião das discussões da Ação de Descumprimento de Preceito Fundamental, a liberdade da mulher não foi manifestamente discutida. Os argumentos giraram em torno da dignidade da pessoa humana, legalidade, liberdade e autonomia da vontade e direito à saúde. O cerne da argumentação, contudo, era a desclassificação da antecipação terapêutica do parto do feto da tipificação do aborto, porque esse último pressupõe viabilidade de vida extrauterina, enquanto o feto anencéfalo não. ${ }^{12}$

A segunda mulher que se manifestou foi a professora Maristela Pezzini, mestre em Direito. Ela enfatizou a importância da família e a relação orgânica entre família, vida e sociedade.

Mais três palestrantes homens foram ouvidos: Aridney Loyelo Barcellos, Presidente da Confederação Nacional das Entidades de Família, Caio de Souza Cazarotto, autor de dissertação intitulada $\mathrm{O}$ direito à vida do Nascituro: em busca da efetividade do direito e o Professor José Levi Mello do Amaral Júnior, professor da Universidade de São Paulo e Secretário Executivo do Ministério da Justiça.

\subsection{0 voto do relator: o deputado Jorge Tadeu Mudalen.}

O relator evidenciou que a proteção jurídica destinada aos recém-nascidos prematuros encontra guarida em diversos dispositivos da legislação, como no Código Civil, em seu Art. $2^{\circ}$, segundo o qual a lei põe a salvo, desde a concepção, os direitos do nascituro, dispositivo já previsto no Código Civil de 1916. Além da criminalização do aborto no Código Penal, a inviolabilidade do direito à vida, a Lei de Alimentos Gravídicos, entre outros, todos preveem a proteção do nascituro.

Dessa forma, o resguardo dos direitos do recém-nascido, desde a sua concepção, no ordenamento jurídico não se coaduna com a tentativa de descriminalização do aborto, tampouco com a posição do STF no julgamento da ADPF $n^{\circ} 442$. Sublinha ele que temas candentes, como a proteção à vida, devem ser

\footnotetext{
12 Para mais: STF, Ação de descumprimento de preceito fundamental $n^{\circ} 442$, relator min. 
afetos ao poder legislativo, sob pena de beirar ao autoritarismo das decisões monocráticas, malferindo a tripartição de poderes, esteio da República.

\subsection{0 projeto final}

Art. 10- $O$ inciso XVIII, do art. 70 da Constituição Federal, passa a vigorar com a seguinte redação: "Art. 70: (...) XVIII - licença à gestante, sem prejuízo do emprego e do salário, com a duração de cento e vinte dias, estendendo-se, em caso de nascimento prematuro, à quantidade de dias que o recém-nascido passar internado, não podendo a licença exceder a duzentos e quarenta dias"

Art. $2^{\circ}$ - Dê-se a seguinte redação ao inciso III do art. $1^{\circ}$ da Constituição Federal: "Art. $1^{\circ}(\ldots)$

III- dignidade da pessoa humana, desde a concepção;

Art. $3^{\circ}$ - Dê-se a seguinte redação ao caput do art. $5^{\circ}$ da Constituição Federal: 'Art. $5^{0}$ Todos são iguais perante a lei, sem distinção de qualquer natureza, garantindo-se aos brasileiros e aos estrangeiros residentes no País a inviolabilidade do direito à vida desde a concepção, à liberdade, à igualdade, à segurança e à propriedade, nos termos seguintes: (...)

Art. 40 - Esta Emenda Constitucional entra em vigor na data de sua publicação.

No ordenamento jurídico brasileiro não há definição doinício da vida. 0 Código Civil faz referência aos direitos do nascituro, sem, contudo, definir o termo inicial.

A esse respeito, aliás, 3 (três) teorias doutrinárias dentro do Direito Civil discutem qual seria o termo inicial dos direitos da personalidade. Não é objeto de discussão neste trabalho perscrutar à respeito dessas teorias. Contudo, a teoria concepcionista foi agasalhada pelo Superior Tribunal de Justiça. Segundo essa teoria, o nascituro desde a concepção possui direitos da personalidade, muito embora, alguns deles apenas sejam exercitáveis com o nascimento. ${ }^{13}$

A introdução na Constituição Federal da expressão "desde a concepção" pode dar margem a inúmeras Ações Diretas de Inconstitucionalidade versando sobre a inconstitucionalidade das hipóteses de aborto já permitidos por lei.

Ademais, a Proposta de Emenda Constitucional definiria o início da vida, a concepção.

\footnotetext{
${ }^{13}$ STJ, Direito Civil. Indenização referenteao seguro DPVAT em decorrência de morte de nascituro. REsp 1.415.727-SC, Rel. Min. Luis Felipe Salomão, julgado em 4/9/2014.
} 
A implicação jurídica e problemática desse texto é que a discussão sobre o aborto encontraria um óbice jurídico. Afinal, como abarcar outras hipóteses de aborto se o início da vida é a concepção?

Boiteux (2016) destaca que Portugal em 2007, por plebiscito, descriminalizou o aborto voluntário até 10 semanas de gestação, prevendo um prazo mínimo de reflexão de três dias. Sublinha-se que Portugal foi um dos últimos países europeus a descriminalizar o aborto e isso foi em 2007. Em 2017, alguns conservadores no Brasil esforçam-se para obstaculizar o debate.

Hoje, o Código Penal permite o aborto nas seguintes situações: se não há outro meio de salvar a vida da gestante e se a gravidez resulta de estupro e o aborto é precedido de consentimento da gestante ou, quando incapaz, de seu representante legal (art. 128, CP).

Além das situações acima descritas, o Supremo Tribunal Federal criou a hipótese extralegal de aborto de feto anencéfalo na ADPF $n^{\circ} 442$.

A criminalização do aborto é uma questão inscrita no território da moralidade e insculpida em uma legislação datada de 1940, portanto, anacrônica e dissonante dos direitos femininos conquistados ao longo dos anos.

Boiteux destaca que a criminalização deste crime é uma forma de controle do corpo da mulher pelo Estado. Em verdade, a mulher que aborta rompe com o papel social que à ela é dado.

A criminalização do aborto não obsta que o crime aconteça, apenas impede que a mulher o faça de forma segura, vitimando sobretudo mulheres pobres que recorrem a clínicas clandestinas de péssimas condições.

\section{UM DIÁLOGO COM MÁRCIA TIBURI}

$\mathrm{Na}$ análise do relatório da comissão, no qual se expõe as razões da emenda constitucional fica evidente que os espaços de fala, assim denominado por Marcia Tiburi (TIBURI, 2015), são proeminentemente masculinos. Em um universo de 8 (oito) pessoas, 6 (seis) eram homens. Homens que discutiam a respeito do corpo da mulher. 
Assim como explana Tiburi, "homens falam sobre o aborto, mulheres - com raras exceções - parecem não se sentir confortáveis em defender a própria causa" (TIBURI, 2015)

Tiburi explana o patriarcado para além de um modelo racional de ética e estética, mas uma prática cotidiana que silencia as mulheres e as repelem dos espaços de discurso.A bem da verdade, a mulher decidir sobre o próprio corpo é uma afronta à hegemonia masculina nos espaços de poder e, por conseguinte, de domínio do discurso.

O patriarcado constrói modelos ideais de mulher: a famigerada mulher honesta, que até 2005 - sim, 2005, apenas há 8 anos - era mencionada no Código Penal. Boiteux bem lembra: o casamento com o estuprador era uma causa extintiva da punibilidade. (BOITEUX, 2016)

O Estado excluía da proteção penal mulheres com vida sexual ativa para além das fronteiras institucionais da família. Portanto, a prostituta não poderia ser vítima do estupro. Assim como a esposa, pois o sexo era parte integrante dos deveres conjugais da mulher.

Uma observação se faz importante: a instituição do casamento, notadamente, a católica, é, de per si, machista, reproduzindo o papel secundário da mulher na sociedade. $O$ pai, durante a liturgia religiosa, conduz a mulher até o noivo. Nada mais é que uma metáfora que traduz a tradição da custódia da mulher do pai para o consorte.

Tiburi aduz: "no senso comum brasileiro vige o discurso de que a realização das mulheres está na maternidade e na feminilidade. Quem não obedecer a esta ordem do discurso poderá ser punida cruelmente" (TIBURI, 2015). As mulheres que optam por não ter filhos são estigmatizadas, achincalhadas, como se um parceiro e crias fossem fatalmente o destino de toda e qualquer fêmea.

A verdade é: retiram a opção das mulheres de decidirem a respeito de seus próprios corpos, obrigando-as a se reproduzir para cumprir sua função social. "Uma mulher deve calar, como se a fala articulada, que expõe ideias, fosse contra a natureza das mulheres e não uma construção jurídico-cultural" (TIBURI, 2015). É dessa forma que a comissão trata as duas mulheres que omitem opinião no texto. A 
elas é destinado tão somete 4 (quatro) parágrafos, enquanto os demais palestrantes ocupam todo o texto de 16 (dezesseis) páginas.

Repisa-se, o patriarcado reduz o espaço de fala das mulheres, impedindo a comunicação, o debate.

Contudo, um paradoxo: o relator, o deputado Jorge Tadeu Mudalen, alerta para a necessidade da ampliação do discurso com sujeitos contra o aborto. No entanto, impõe uma modificação no texto Constitucional sem ouvir àquelas favoráveis à causa.

A liberdade de pensamento e manifestação não é apenas um direito fundamental consagrado na Constituição. Ele deve ser exercitado e estimulado, especialmente por aqueles que ocupam espaços de poder, seja homem, seja mulher.

\section{CONSIDERAÇÕES FINAIS}

Evidentemente que as conquistas na luta contra a violência contra a mulher, em especial com a Lei Maria da Penha e do feminicídio, são indiscutíveis: o avanço ocorreu e está em progresso no Brasil. O que até a Constituição de 1988 foi ignorado, passou a ocupar as pautas do Congresso e das cortes superiores.

$O$ ingresso das mulheres nos espaços de poder deu maior visibilidade à agenda feminista. Contudo há um intenso movimento na tentativa de frear esses avanços, não apenas no que se refere ao movimento feminista, mas a todos os movimentos minoritários de maneira geral, como os movimentos LGBT+, indigenista e negro.

A luta por direito nunca está assegurada, mas em constante processo de aprimoramento. Ocupar os espaços de poder é fundamental para levantar questões afetas a grupos que tradicionalmente foram excluídos do processo político.

O avanço é inegável. A luta por direitos urgente.

\section{REFERÊNCIAS}

BRASIL. Decreto-lei no 3.689, de 3 de outubro de 1941. Código de Processo Penal. Disponível em: http://www.planalto.gov.br/ccivil_03/decreto-lei/Del3689.htm. Acesso em: 4 abr. 2019. 
BRASIL. Lei no 11.340, de 7 de agosto de 2006. Cria mecanismos para coibir a violência doméstica e familiar contra a mulher, nos termos do $\S 8^{\circ}$ do art. 226 da Constituição Federal, da Convenção sobre a Eliminação de Todas as Formas de Discriminação contra as Mulheres e da Convenção Interamericana para Prevenir... Disponível em: http://www.planalto.gov.br/ccivil_03/_Ato20042006/2006/Lei/L11340.htm. Acesso em: 4 abr. 2019.

BOITEUX, Luciana. A legalização do abortoe o feminismo: amanhã vai ser outro dia. Folha de São Paulo, São Paulo, 8 jul. 2016.

PINTO; Andréia Soares; MORAES, Orlinda Cláudia R. de; MANSO, Flávia Vastano (Org.). Dossiê Mulher 2017. Rio de Janeiro: Instituto de Segurança Pública, 2017.

TIBURI, Márcia. 0 aborto e a bondade dos outros. Disponível em: http://www.marciatiburi.com.br/textos/oabortodosoutros.htm. Acesso em: 16 fev. 2018. 